\title{
In-situ reforming of the volatiles from fast pyrolysis of ligno-cellulosic biomass over zeolite
} catalysts for aromatic compounds production

Kazuhiro Uemura $^{1}$, Srinivas Appari ${ }^{2}$, Shinji Kudo ${ }^{2}$, Jun-ichiro Hayashi ${ }^{1,2,3}$, Hisahiro Einaga ${ }^{4}$, and Koyo Norinaga ${ }^{1,2, *}$

${ }^{1}$ Interdisciplinary Graduate School of Engineering Sciences, Kyushu University, Kasuga 8168580, Japan

${ }^{2}$ Institute for Materials Chemistry and Engineering, Kyushu University, Kasuga 816-8580, Japan

${ }^{3}$ Research and Education Center of Carbon Resources, Kyushu University, Kasuga 816-8580, Japan

${ }^{4}$ Department of Energy and Material Sciences Faculty of Engineering Sciences, Kyushu University, Kasuga 816-8580, Japan

\section{ABSTRACT}

Characteristics of in-situ catalytic reforming of the products derived from fast pyrolysis of biomass were studied with an originally designed analytical pyrolysis technique. The volatile products derived from ligno-cellulosic biomass as well as cellulose, xylan, and lignin were converted using a two-stage tubular reactor at $550{ }^{\circ} \mathrm{C}$ over various zeolite catalysts with different acidities and pore structures. HZSM-5 exhibited the best performance for converting the cedar derived volatiles to arenes, which mainly composed of benzene, toluene, and naphthalene with a selectivity of $26 \%$ on carbon basis. The HZSM-5 had a little effect in increasing the yields of the 
1 arenes for xylan and lignin, whilst it had a significant effect for cellulose, showing that more than

$230 \%$ of carbon in cellulose was converted into arenes. A reaction pathway analysis for reforming

3 of volatiles suggested that alkyne and diene such as acetylene, propyne, and cyclopentadiene are

4 the important precursors of the major aromatic hydrocarbon products such as benzene, toluene,

5 and naphthalene. The formations of those intermediates were also confirmed experimentally in

6 an early stage of the in-situ reforming.

7

$8 \quad$ * Corresponding author. Tel.: +81 92583 7794; fax: +81 925837793.

9 E-mail address: norinaga@cm.kyuhsu-u.ac.jp (Koyo Norinaga).

10 Keywords

11 Catalytic reforming; Reaction mechanism; Nascent volatiles from ligno-cellulosic biomass;

12 Arenes; Zeolite catalysts

13 
2 Ligno-cellulosic biomass such as agricultural residues, short rotation woody crops, herbaceous

3 crops, forestry residues, and waste paper is considered to be a promising source for renewable

4 liquid fuel [1-3]. The fast pyrolysis of biomass is one of the viable processes to convert it into

5 liquid fuels, which are referred to as bio-oil. Bio-oil is considered to be as a promising alternative

6 fuel, produced by simple methods with high efficiency $[4,5]$. However, the quality of bio-oil is

7 much lower than that of the conventional petroleum-based oil because of its thermal instability,

8 acidic nature, and low calorific value [6]. The effective upgrading techniques are needed to meet

9 the standards of the conventional fuel [7-9].

10 Catalytic reforming is one of the promising ways to upgrade crude bio-oil. There are few reports

11 that investigate in-situ reforming of volatiles derived from the fast pyrolysis of biomass [10-12].

12 For example, Carlson et al. [11], investigated the conversion of biomass into aromatics by

13 thermal decomposition in the presence of zeolite catalysts using pyroprobe analytical pyrolyzer.

14 They reported that more than $30 \%$ aromatic compounds were obtained from cellulose with 15 zeolite catalyst $\left(\mathrm{ZSM}-5, \mathrm{SiO}_{2} / \mathrm{Al}_{2} \mathrm{O}_{3}=60\right)$ at the optimal reactor conditions. The high conversion

16 efficiency from those carbohydrates which are free from aromatic structures to aromatics should

17 be of great interest. However, the mechanistic interpretations for this process are limited since

18 the complex processes such as primary pyrolysis and reforming of volatiles over catalysts as well

19 as nascent char are simultaneously occurred in the pyroprobe reactor. The volatile-char

20 interaction is known to have a positive effect on tar destruction [13, 14].

21 The objective of this work is to study experimentally the in-situ reforming characteristics of the

22 products from the fast pyrolysis of biomass over various zeolite catalysts under minimized

23 volatile-char interactions by using a two-stage tubular reactor which is directly connected to a 
1 gas analysis system. The tubular reactor was divided into two zones by a filter, the first zone is

2 used for fast pyrolysis of biomass, and the other zone is used for catalytic reforming. The reactor

3 has a set-up to control the contact times of the nascent volatiles over the catalyst. Moreover, a

4 reaction pathway included in the conversion into arenes is also proposed based on the detailed

$5 \quad$ chemical kinetic model proposed previously [15].

\section{2. Experimental}

7 Biomass pyrolysis with in-situ catalytic reforming experiments were carried out in a U- shaped 8 two-stage tubular reactor (TS-TR) at $550{ }^{\circ} \mathrm{C}$. All the fast pyrolysis with reforming experiments 9 were carried out at $550{ }^{\circ} \mathrm{C}$ in the presence of inert gas helium or nitrogen. A schematic 10 representation of the reactor is shown in Fig. 1. The TS-TR was made-up of quartz and divided

11 into two zones by a quartz wool filter, the first zone is used for fast pyrolysis of the biomass and 12 second is used for catalytic reforming of volatiles derived from the biomass on zeolite catalysts.

13 The second zone of the reactor is loaded with catalyst zeolite particles. Table 1 shows the 14 characteristics of the five zeolites with different acidity and pore size. All catalysts are purchased 15 from Zeolyst International and Tosoh. The inner diameters of the pyrolysis zone and the 16 reforming zone were 6 and $4 \mathrm{~mm}$, respectively.

17 Japanese cedar (C: 50.2; H: 6.3; O: $42.3 \mathrm{wt} \%$, dry basis), cellulose (Sigma Aldrich), lignin 18 (Kishida Chemical Co., Japan), and xylan (Tokyo Chemical Industry, Japan) were used as 19 samples in this study. Sawdust of cedar was used and the diameter was in the range of 0.50 to $201.18 \mathrm{~mm}$. Xylan was used as a model compound for hemicellulose. Approximately $1.0 \mathrm{mg}$ of the 21 sample was wrapped with a sheet of stainless (SUS316) wire mesh with a mesh opening of 45

$22 \mu \mathrm{m}$ and dried in vacuum oven at room temperature overnight. The mass of the wrapped sample 23 was measured immediately after drying to determine the exact dry mass of the sample, which 
was subsequently fixed at the upper part of the TS-TR. The reactor was heated to $550{ }^{\circ} \mathrm{C}$ by external furnace, after stabilizing the heated section of the TS-TR, the sample was dropped into the bottom of the first tube, where the biomass sample was fast-pyrolyzed. The volatiles and char were formed in the first zone of the reactor. The volatiles released were subsequently swept off into the catalyst bed for reforming. The residence time $(0.02$ to $0.16 \mathrm{~s}$ based on catalyst bed length) of the volatiles in the catalytic zone was controlled by the amount of loaded catalyst varying from 0.012 to $0.11 \mathrm{~g}$ in the second zone of the reactor.

The reformed products were introduced into gas chromatographs (Shimadzu GC 2014 or GC 2010) with helium or nitrogen used as carrier gas. The products were exhaustively analyzed by using three different columns and two different detectors (TCD and FID). More than 40 compounds were identified and quantified. Inorganic gasses such as $\mathrm{H}_{2}, \mathrm{CO}, \mathrm{CO}_{2}$, and $\mathrm{H}_{2} \mathrm{O}$ were separated by Gaskuropack 54 column (GL Sciences Co. Ltd) and detected with TCD. The packed column Gaskuropack 54, consists of polymer beads with highly cross linked styrenedivinylbenzene copolymer, can able to separate these products. Light hydrocarbons such as alkanes, alkenes, and alkynes, and oxygenated compounds such as methanol, ethanol, acetaldehyde, furan, acetone, propanol, acetic acid, hydroxyl acetone, furfural, and furan were quantified by the same column with FID. Another packed column VZN-1 (GL Sciences Inc.) is used for separating alkene, alkyne, and diene with FID. Since the packed columns have some limitations in detecting high-molecular weight compounds, these compounds were quantified by GC equipped with a capillary column (CP PoraBOND, Agilent Technology, Co. Ltd). High molecular weight compounds such as mono- and bicyclic aromatic compounds were detected by PoraBOND column. The quantifications of the products were conducted based on the external calibration method which uses response vs amount functions that are subsequently used to 
1 estimate amounts of analyte in a separately analyzed sample as long as the standard compounds

2 for the target products were available. The effective carbon number concept [16] was also

3 employed for estimation of the amounts of products of which standards were unavailable. The

4 detailed procedure was published elsewhere [17]. The product yields were calculated based on

5 the carbon content in the feedstock. The yields were calculated according to the equation

$$
Y_{i}=\frac{A_{i}}{\left(\frac{A_{C H 4}}{N_{C H 4}}\right) * R} * M_{i} * x_{i} * \frac{1}{W_{c-\text { feed }}}
$$

7 Where, $Y_{i}$ is the yield of $i^{\text {th }}$ component (mol-C/ mol-C in feed), $A_{i}$ is peak area in the

8 chromatogram, $R$ is the relative response, $x_{i}$ is the ratio carbon weight to the molecular weight of

$9 i^{\text {th }}$ component, and $W_{\text {c-feed }}$ is the carbon weight in cedar, and $N_{\mathrm{CH}}$ is the moles of $\mathrm{CH}_{4}$ in the 10 standard gas.

\section{3. Results and Discussion}

\section{3.1. Non-catalytic experiment}

13 The volatile products derived from the fast pyrolysis of cedar at $550{ }^{\circ} \mathrm{C}$ without catalyst in the

14 second zone of the reactor were analyzed by different columns. Typical GC/FID chromatograms

15 along with the assigned peaks are shown in Fig. 2. Fig. 2a shows the Gasukuropak54

16 chromatogram of inorganic compounds that are identified by the TCD. The same column was

17 also used with FID to detect light hydrocarbons such as alkanes, alkenes, alkynes, and

18 oxygenated compounds such as alcohol, aldehyde, and furan and respective chromatograms are

19 shown in Fig. 2b. However, this column cannot separate acetylene with ethylene. Another

20 packed column (VZN-1) was employed to separate and quantification of the alkyne and dienes 
1 which are shown in Fig. 2(c). As shown in Fig. 2d, CP PoraBOND column is able to detect

2 compounds larger than toluene such as alkylbenezne, phenol and naphthalene.

\section{3.2. Effect of catalyst on catalytic reforming of cedar volatiles}

4 The volatiles from the fast pyrolysis produce water and dehydrated species by hydration

5 reactions, which can occur in the gas phase or in the catalytic surface. These hydrated species are

6 further converted into aromatics, hydrocarbons, water, and so on by a series of reactions in the

7 presence of zeolite catalysts [11]. Fig. 3 shows the chromatographs of catalytic reforming of

8 volatiles derived from cedar in the presence of $0.11 \mathrm{~g}$ of $\mathrm{HZSM}-5\left(\mathrm{SiO}_{2} / \mathrm{Al}_{2} \mathrm{O}_{3}=23\right)$ at $550{ }^{\circ} \mathrm{C}$.

9 These chromatograms show (Fig 3) the very large intensities for hydrocarbons and aromatic

10 compounds such as benzene, toluene, and naphthalene. For instance, benzene peaks in Fig 2 are

11 very low compared with the peak intensity in Fig 3, and similar type of observations can be

12 drawn even for hydrocarbons. The peak intensity areas for hydrocarbons are also increased in the

13 presence of zeolite catalysts. The large differences in these chromatographs indicate that the

14 presence of zeolite catalysts have obvious effects on the conversion of volatiles derived from the 15 fast pyrolysis of cedar.

16 The catalytic reforming experiments were carried out with different zeolite compositions loaded

17 in the second zone of the reactor. In order to get the quantitative information as well as the effect

18 of catalysts on the product distributions, five kinds of zeolite catalysts were used in this study.

19 Fig. 4 shows the product yields (carbon basis) of volatiles derived from fast pyrolysis of cedar on

20 different zeolite type catalysts at $550{ }^{\circ} \mathrm{C}$. The product yields without catalyst is also shown for

21 comparison in Fig. 4. It is obviously observed that the product yields such as hydrocarbons and

22 aromatics showed higher values in the presence of catalysts. HZSM-5 is more active for

23 promoting the formation of arenes than other zeolite catalysts used. When HZSM-5 was used, 
1 the arenes yield increased from 4.6 to $26 \%$, while the oxygenated compounds yield decreased

2 from 6.6 to $0.3 \%$, in comparison with non-catalytic experiment. The catalyst Y-type-2 $\left(\mathrm{SiO}_{2} /\right.$

$3 \mathrm{Al}_{2} \mathrm{O}_{3}=400$ ) showed lower aromatic yield than any other catalysts. The yield of aromatics for

4 the different zeolite catalysts is in the order of HZSM-5 $>$ Mordenite $>$ Y-type-1 $>\beta$-type $>$ Y-

5 type-2. Fig.4. also reveals that the catalyst Y-type-2 is less effective in converting the

6 oxygenated compounds than any other zeolite catalysts.

7 The catalyst HZSM-5 is more effective in converting the oxygenated compounds and decreasing

8 conversion in the order of Y-type-1, mordenite, $\beta$-type, and Y-type-2. This is mainly due to

9 higher silica to alumina ratio in the zeolite $\mathrm{Y}$-type-2 $\left(\mathrm{SiO}_{2} / \mathrm{Al}_{2} \mathrm{O}_{3}=400\right)$ catalyst. The low ratio

10 of silica to alumina catalyst has more effective in decomposition of oxygenated compounds. It is

11 also inferred from the Fig. 4, the conversion characteristics of HZSM- 5 was different from those

12 with mordenite, even though both the catalysts have similar silica to alumina ratio. This indicates

13 that the frame structure of zeolite is also an important parameter in the catalyst reforming.

\section{3.3. Effect of catalyst on catalytic reforming of model compound}

15 The in-situ catalytic reforming on HZSM-5 catalyst was also carried with individual

16 components of cedar volatiles derived from fast pyrolysis. Ligno-cellulosic biomass such as

17 cedar mainly consists of three components namely cellulose, hemicellulose, and lignin. Xylan

18 was used as a model compound for hemicellulose. The catalytic reforming products distribution

19 of fast pyrolysis of individual components of cedar such as cellulose, lignin, and xylan on

20 HZSM-5 were shown in Fig. 5. The presence of catalyst increases the aromatic product yields in

21 all the individual components of cedar. The similar trends are also observed in the yields

22 hydrocarbon $\left(\mathrm{C}_{1}-\mathrm{C}_{5}\right)$. The presence of catalyst converts the most of the oxygenated compounds 
1 present in the individual components of cedar. This also reconfirms the catalytic effect on

2 volatiles derived from the fast pyrolysis of cedar.

3 The cedar component of cellulose has shown maximum aromatic yield, whereas lignin and

4 xylan showed lower aromatic compounds yields in the presence of catalyst HZSM-5. The

5 aromatic yields showed maximum for cellulose, intermediate for lignin, and minimum for xylan.

6 It is most likely that the cellulose content in biomass contributes to the formation of aromatic

7 compounds. The ligno-cellulosic biomass such as cedar mainly contains about $40-47 \mathrm{wt} \%$ of

8 cellulose $[18,19]$.

9 Thring et al. [21] converted the organosolv lignin dissolved in the double amount of acetone 10 over HZSM-5 at $500-650^{\circ} \mathrm{C}$ and WHSV of $2.5-7.5 \mathrm{~h}^{-1}$ using a fixed bed flow reactor. One of

11 the results showed that they succeeded to get aromatic of lignin with $38 \%$ yield at $550{ }^{\circ} \mathrm{C}$ and

12 WHSV $=5 \mathrm{~h}^{-1}$. In our case of the cracking of nascent volatiles derived from lignin over HZSM-

135 , we could get aromatic hydrocarbons with the yield of $12 \mathrm{~mol}-\mathrm{C} \%$ (corresponds to $7 \mathrm{wt} \%$ of

14 lignin fed) as shown in Fig.5. The possible reason for the lower yield observed in our case is

15 likely to be a very different experimental condition. As evidenced by Thring et al. [21], acetone

16 converted into gaseous products such as ethylene, propylene, and propane almost completely

17 over HZSM-5 at a condition $600{ }^{\circ} \mathrm{C}$ and WHSV $=5 \mathrm{~h}^{-1}$ typically used in their experiments. This

18 means that reactive radicals are occurring during lignin decomposition process and likely

19 contribute to quench radicals formed from lignin depolymerization, thereby reducing charring and increasing the liquid product yields. On the other hand, in our experiments, reforming of

21 nascent volatiles from lignin fast pyrolysis over HZSM-5 underwent in the presence of inert

22 carrier gas like helium. This results in the higher char and lower aromatic hydrocarbons (liquid 
2 lignin/actone mixture as a feed by Thring et al. [21].

\section{$3 \quad$ 3.4. Reaction pathways leading to arenes}

4 There are no interpretations available for the arenes formations in the in-situ reforming of multi-

5 component mixtures derived from cellulose fast pyrolysis over a zeolite catalyst at mechanistic

6 level. The authors developed a detailed chemical kinetic model for describing the vapor phase

7 i.e., non- catalytic reforming of cellulose [15]. Based on this kinetic model, a reaction pathway

8 for aromatic compounds formation is proposed and shown in Fig. 6. The fast pyrolysis of

9 cellulose produces mainly levoglucosan, furfural, D-glyceraldehyde, hydroxyl acetaldehyde, 5-

10 HMF, and hydroxyl acetone, which were also confirmed by Shin et al [20]. These volatiles are

11 further converted into reforming products in the presence of zeolite catalysts. It is suggested that

12 dehydrogeneation and cracking of volatiles take place on the surface of the zeolite catalyst.

13 These reactions produce intermediates mainly short chains of alkanes and alkenes. According to

14 this proposed mechanism, alkenes and dienes such as acetylene, propyne, and cyclopentadiene

15 are the important intermediates to the arenes formation. The formation of intermediates such as

16 alkenes and dienes were confirmed from the vapor phase cracking of nascent volatiles derived

17 from cellulose $[15,17]$.

18 The proposed reaction pathway shows that aromatic benzene is formed mainly from two routes;

19 the first one is the decomposition of toluene, and the second is from $\mathrm{C}_{3}$ hydrocarbons such as

20 propadiene and propyne. Toluene is formed almost exclusively by the combination of

21 cyclopentadiene with ethylene. Cyclopentadiene is formed mainly by the combination of allyl

22 radicals and acetylene. Allyl radical is formed from butane and propylene, both of which are

23 major constituents of the primary pyrolysis products of cedar. Acetylene is likely produced from 
1 the dehydrogenation of ethylene. Benzene formation from $\mathrm{C}_{3}$ hydrocarbons is formed from the

2 propylene, which is from the decomposition of furan.

3 The reforming experiments with fast pyrolysis were also carried out with varying amount of

4 catalyst HZSM-5 in the second zone of the reactor to follow the formation profiles of these

5 important intermediates kinetically. Fig. 7 shows the yields (carbon basis) of alkynes and

6 cyclopentadiene. The yields are increased with increased catalyst loading, and further increase

7 the catalyst loading, the yields were decreased. When the catalyst loading is $0.05 \mathrm{~g}$, acetylene

8 and propyne showed maximum yields. The yield of cyclopentadiene is maximum when the

9 catalyst loading is $0.02 \mathrm{~g}$. The formation of alkyene and diene compounds in the catalytic

10 reforming of multicomponent mixture derived from cellulose fast pyrolysis play a major role in

11 the formation of aromatics. It should be noted that many monomers in lignin are considered to

12 have a $\mathrm{C}_{6}-\mathrm{C}_{3}$ (phenyl propanoid) structure [21]. It is thus possible that ethylene and propylene

13 are also produced not only from cellulose but also from lignin by cleavage of lignin side chains

14 ( $\mathrm{C}_{3}$ portion) to give aromatic compounds.

15 4. Conclusions

16 In-situ reforming of volatiles derived from the fast pyrolysis of cedar were studied at $550{ }^{\circ} \mathrm{C}$.

17 Different types of zeolite catalysts were used in this study. The volatiles from the fast pyrolysis

18 undergo reforming on zeolite catalysts by a series of reactions produce aromatics and

19 hydrocarbons. The catalyst HZSM-5 had showed higher efficiency than other catalysts. The

20 experiments with individual components of cedar, one of the component cellulose showed the

21 maximum conversion of biomass into aromatics products. The reaction pathway is also proposed

22 to understand the in-situ reforming kinetics and indicates that aromatic benzene is formed from 
1 two dominating routes. The experiments with varying catalyst loading (HZSM-5) revealed that

2 the formation of alkynes and dienes were playing important roles in the formation of aromatics.

\section{Acknowledgements}

5 Part of this research was funded by the Ministry of Education, Science, Sports and Culture

6 Grant-in-Aid for Young Scientists (No. 23686112) and for Challenging Exploratory Research

7 (No. 24651080), and the MOST-JST, Strategic International Collaborative Research Program, 8 SICORP.

9

\section{References}

11 [1] G.W. Huber, S. Iborra, A. Corma, Synthesis of transportation fuels from biomass: Chemistry, 12 catalysts, and engineering, Chemical Reviews, 106 (2006) 4044-4098.

13 [2] D. Chiaramonti, A. Oasmaa, Y. Solantausta, Power generation using fast pyrolysis liquids

14 from biomass, Renewable and Sustainable Energy Reviews, 11 (2007) 1056-1086.

15 [3] H.B. Goyal, D. Seal, R.C. Saxena, Bio-fuels from thermochemical conversion of renewable resources: A review, Renewable and Sustainable Energy Reviews, 12 (2008) 504-517.

17 [4] A.V. Bridgwater, G.V.C. Peacocke, Fast pyrolysis processes for biomass, Renewable and 18 sustainable energy reviews, 4 (2000) 1-73.

19 [5] S. Czernik, A.V. Bridgwater, Overview of applications of biomass fast pyrolysis oil, Energy 20 \& Fuels, 18 (2004) 590-598.

21 [6] D. Mohan, C.U. Pittman Jr, P.H. Steele, Pyrolysis of wood/biomass for bio-oil: A critical 22 review, Energy \& Fuels, 20 (2006) 848-889. 
1 [7] J. Adam, E. Antonakou, A. Lappas, M. Stöcker, M.H. Nilsen, A. Bouzga, J.E. Hustad, Gisle

2 Øye, In situ catalytic upgrading of biomass derived fast pyrolysis vapours in a fixed bed reactor

3 using mesoporous materials, Microporous and Mesoporous Materials, 96 (2006) 93-101.

4 [8] P.A. Horne, P.T. Williams, Upgrading of biomass-derived pyrolytic vapours over zeolite

5 ZSM-5 catalyst: Effect of catalyst dilution on product yields, Fuel, 75 (1996) 1043-1050.

6 [9] M.I. Nokkosmäki, E.T. Kuoppala, E.A. Leppämäkib, A.O.I. Krause, Catalytic conversion of

7 biomass pyrolysis vapours with zinc oxide, Journal of Analytical and Applied Pyrolysis, 55

$8 \quad(2000)$ 119-131.

9 [10] T.R. Carlson, T.P. Vispute, G.W. Huber, Green gasoline by catalytic fast pyrolysis of solid

10 biomass derived compounds, ChemSusChem, 1 (2008) 397-400.

11 [11] T.R. Carlson, G.A. Tompsett, W.C. Conner, G.W. Huber, Aromatic production from

12 catalytic fast pyrolysis of biomass-derived feedstocks, Topics in Catalysis, 52 (2009) 241-252.

13 [12] T.R. Carlson, Y.T. Cheng, J. Jae, G.W. Huber, Production of green aromatics and olefins by 14 catalytic fast pyrolysis of wood sawdust, Energy and Environmental Science, 4 (2011) 145-161.

15 [13] C.Z. Li, Importance of volatile-char interactions during the pyrolysis and gasification of

16 low-rank fuels - A review, Fuel, 112 (2013) 609-623.

17 [14] Y. Song, Y. Wang, X. Hu, S. Hu, J. Xiang, L. Zhang, S. Zhang, Z. Min, C.Z. Li, Effects of

18 volatile-char interactions on in situ destruction of nascent tar during the pyrolysis and

19 gasification of biomass. Part I. Roles of nascent char, Fuel, 122 (2014) 60-66.

20 [15] K. Norinaga, T. Shoji, S. Kudo, J.I. Hayashi, Detailed chemical kinetic modelling of

21 vapour-phase cracking of multi-component molecular mixtures derived from the fast pyrolysis of

22 cellulose, Fuel, 103 (2013) 141-150. 
1 [16] J.C. Sternberg, W.S. Gallaway, D.T.L. Jones, The mechanism of response of flame

2 ionization detectors, Gas Chromatography, N. Brenner, J.E. Callen, M.D. Weiss (Eds.), Gas

3 chromatography, Academic Press, New York (1962).

4 [17] K. Norinaga, H. Yang, R. Tanaka, S. Appari, K. Iwanaga, Y. Takashima, S. Kudo, T. Shoji,

5 J.I. Hayashi, A mechanistic study on the reaction pathways leading to benzene and naphthalene

6 in cellulose vapor phase cracking, Biomass and Bioenergy, 69 (2014) 144-154.

7 [18] A. Gani, I. Naruse, Effect of cellulose and lignin content on pyrolysis and combustion

8 characteristics for several types of biomass, Renewable Energy, 32 (2007) 649-661.

9 [19] C. Liu, H. Wang, A. M. Karim, J. Suna and Y. Wang, Catalytic fast pyrolysis of

10 lignocellulosic biomass, Chem Soc Rev, DOI: 10.1039/c3cs60414d.

11 [20] E. J. Shin, M. R. Nimlos, R. J. Evans. Kinetic analysis of the gas-phase pyrolysis of

12 carbohydrates. Fuel, 80 (2001) 1697-709.

13 [21] R.W. Thring, S.P.. Katikaneni, N.N. Bakhshi, The production of gasoline range

14 hydrocarbons from Alcell® lignin using HZSM-5 catalyst, Fuel Process. Technol. 62 (2000) 171530.

16

17 


\section{List figure captions}

2 Fig. 1. A schematic representation of the experimental set-up for studying the kinetics of in-situ 3 reforming of volatiles derived from the fast pyrolysis of cedar.

4 Fig. 2. GC chromatograms of volatiles derived from cedar pyrolysis at $550{ }^{\circ} \mathrm{C}$ without catalyst.

5 (A) Packed column (Gaskuropack 54)-TCD, (B) Packed column (Gaskuropack 54)-FID,

6 (C) Packed column (VZN-1)-FID, (D) Capillary column (PoraBOND)-FID.

7 Fig. 3. GC chromatograms of the in-situ reformed products from cedar fast pyrolysis reformed 8 on catalyst (HZSM-5, $0.11 \mathrm{~g}$ ) at $550{ }^{\circ} \mathrm{C}$. (A) Packed column (Gaskuropack 54)-TCD, (B) Packed 9 column (Gaskuropack 54)-FID, (C) Packed column (VZN-1)-FID, (D) Capillary column 10 (PoraBOND)-FID.

11 Fig. 4. Product distributions of the reforming of the products derived from fast pyrolysis of cedar 12 at $550{ }^{\circ} \mathrm{C}$ on different zeolite catalysts $(0.11 \mathrm{~g})$.

13 Fig. 5. Product distributions of the reforming of the products derived from fast pyrolysis of 14 individual components of cedar at $550{ }^{\circ} \mathrm{C}$ on HZSM-5 catalyst $(0.11 \mathrm{~g})$.

15 Fig. 6. A proposed reaction pathway leading to aromatic compounds in in-situ reforming of 16 volatiles derived from the fast pyrolysis of cedar on zeolite catalysts.

17 Fig. 7. Product distribution of alkyne and diene as a function of catalyst loaded amount of 18 HZSM-5 for reforming of products from fast pyrolysis of cedar at $550{ }^{\circ} \mathrm{C}$. 
2 Characteristics of the zeolite catalysts

\begin{tabular}{ccccc}
\hline $\begin{array}{c}\text { Zeolite (Frame } \\
\text { structure) }\end{array}$ & $\mathrm{SiO}_{2} / \mathrm{Al}_{2} \mathrm{O}_{3}$, & $\mathrm{Na}_{2} \mathrm{O}$, & Unit Cell & Surface Area, \\
& 23 & $\mathrm{wt} \%$ & Size, $\AA$ & $\mathrm{m}^{2} / \mathrm{g}$ \\
\hline HZSM-5 & 20 & 0.05 & - & 425 \\
Mordenite & 5.1 & 0.08 & - & 500 \\
Y-type-1 & 2.8 & 24.5 & 730 \\
Y-type-2 & 400 & 0.05 & 500 & 620 \\
$\beta$-type & 500 & 0.1 & 3000 & 400 \\
\hline
\end{tabular}




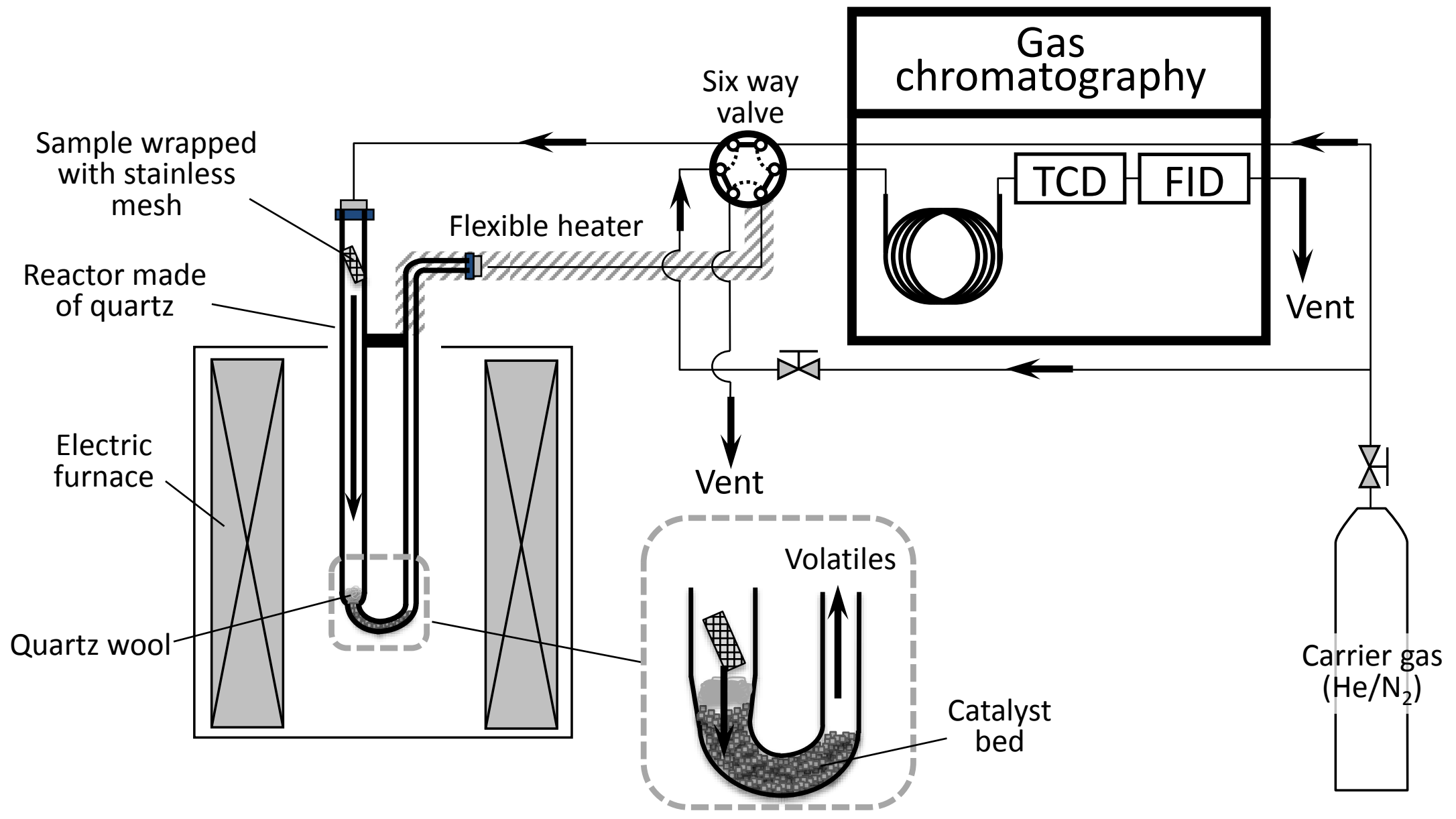

Fig.1. Uemura et al. 

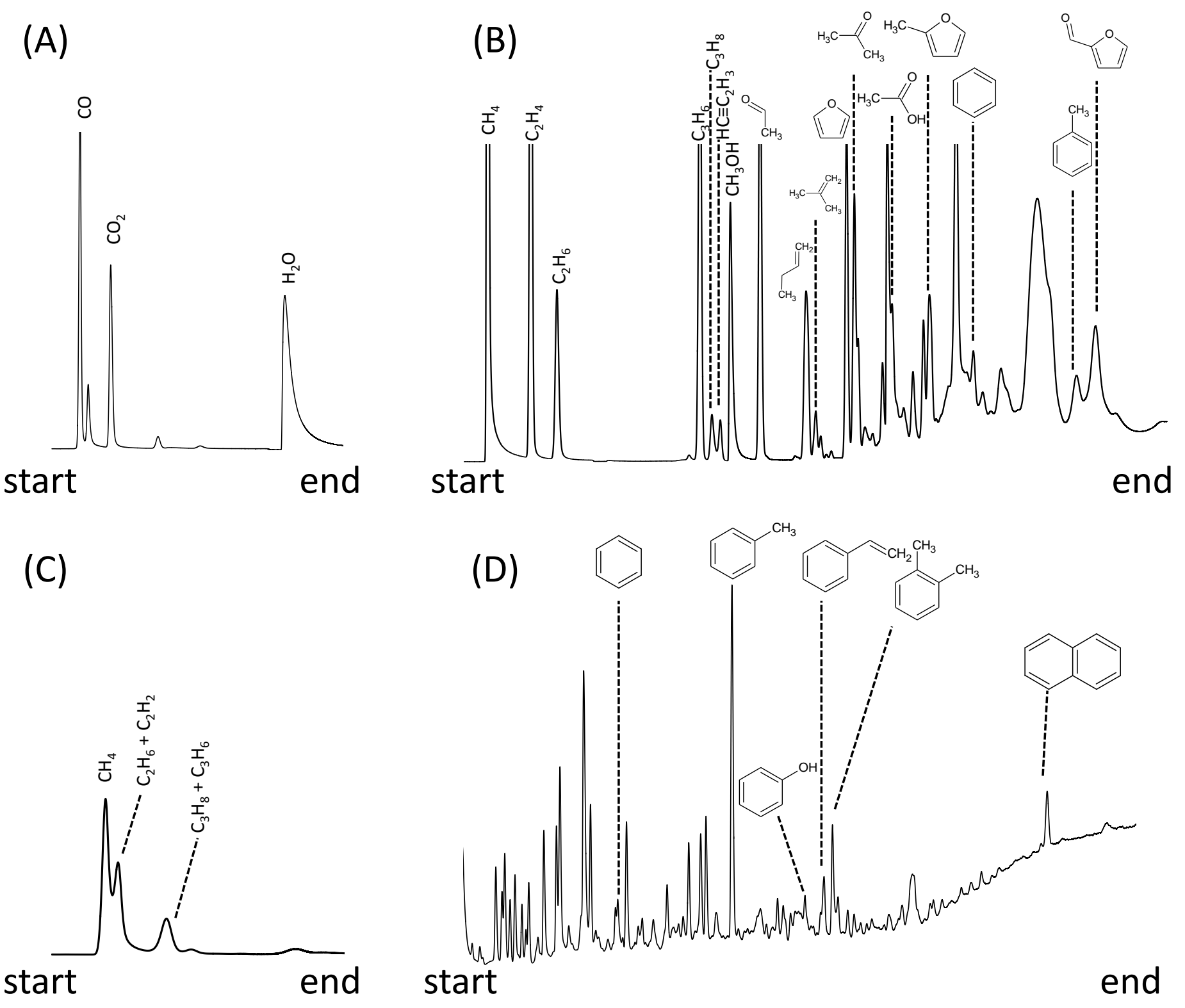

Fig.2. Uemura et al. 
(A)

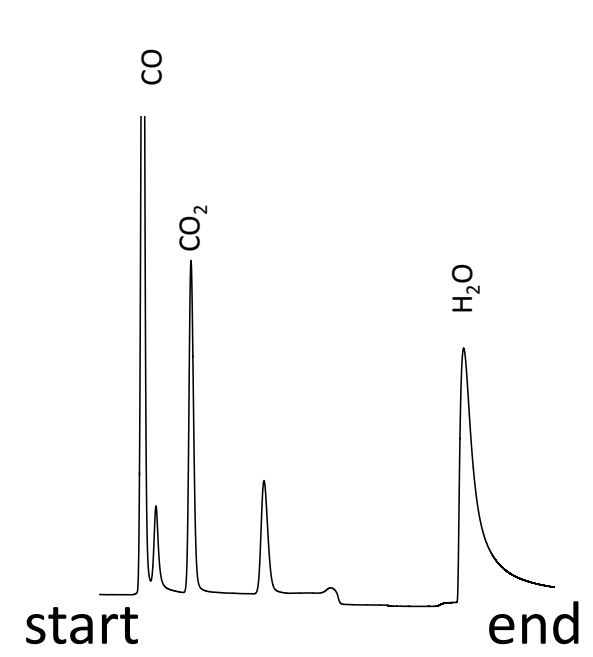

(C) 福

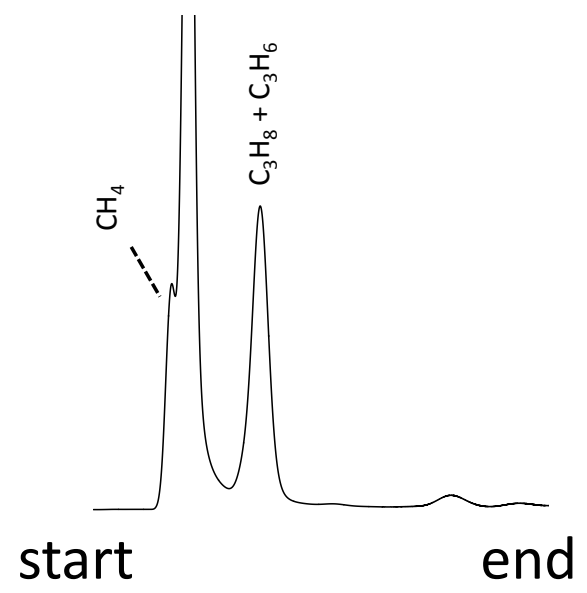

(B)

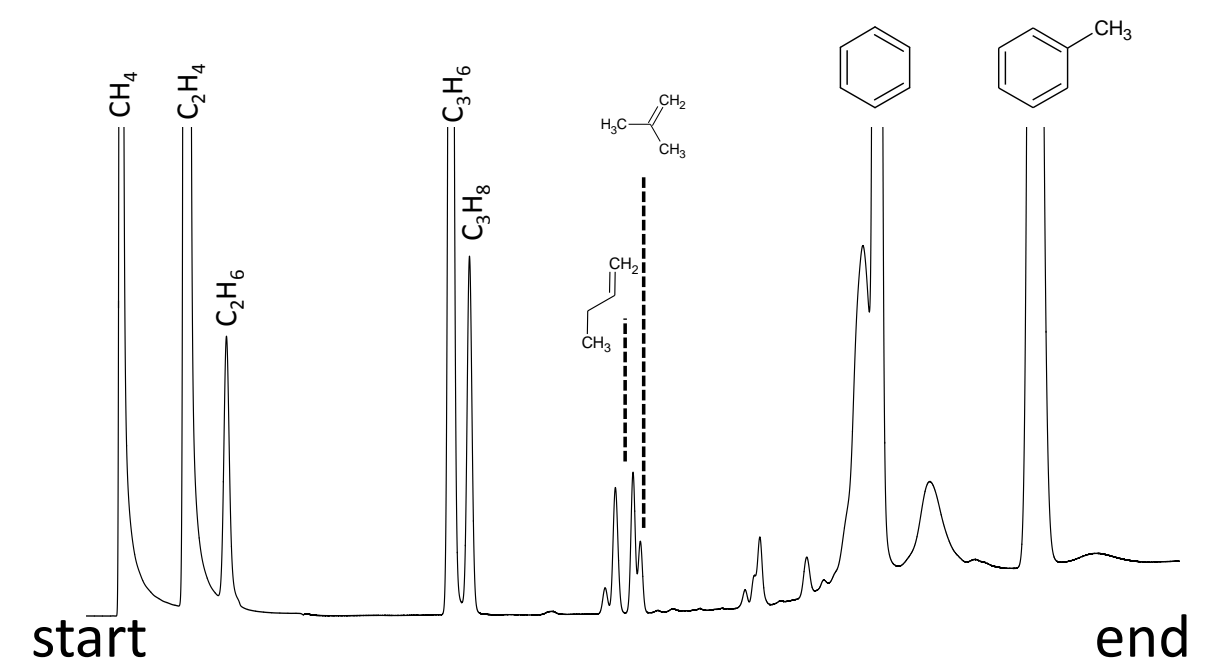

(D)

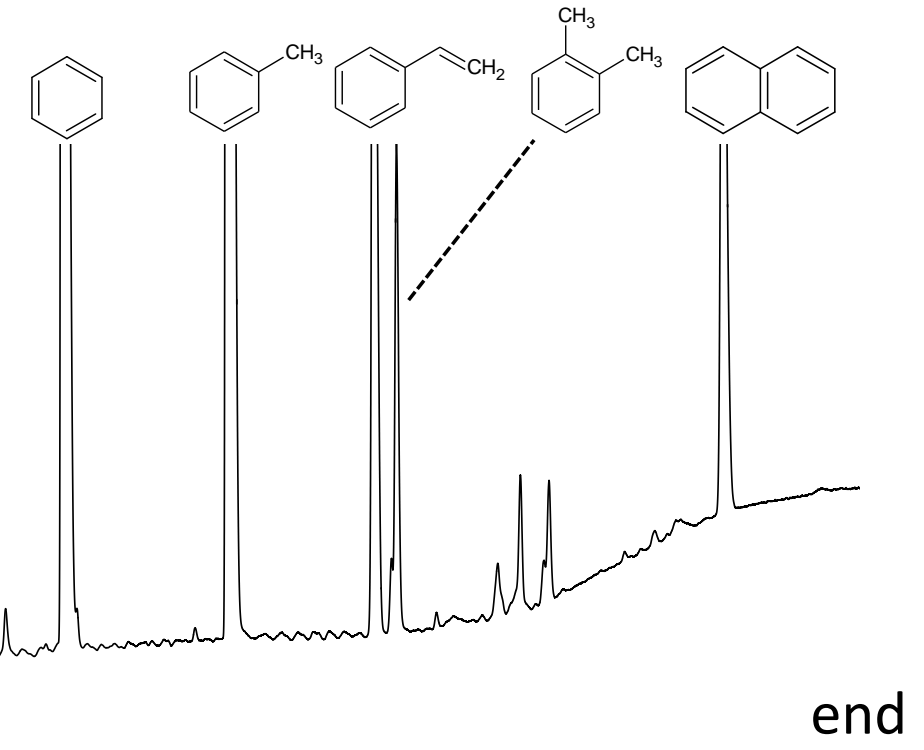

Fig.3. Uemura et al. 


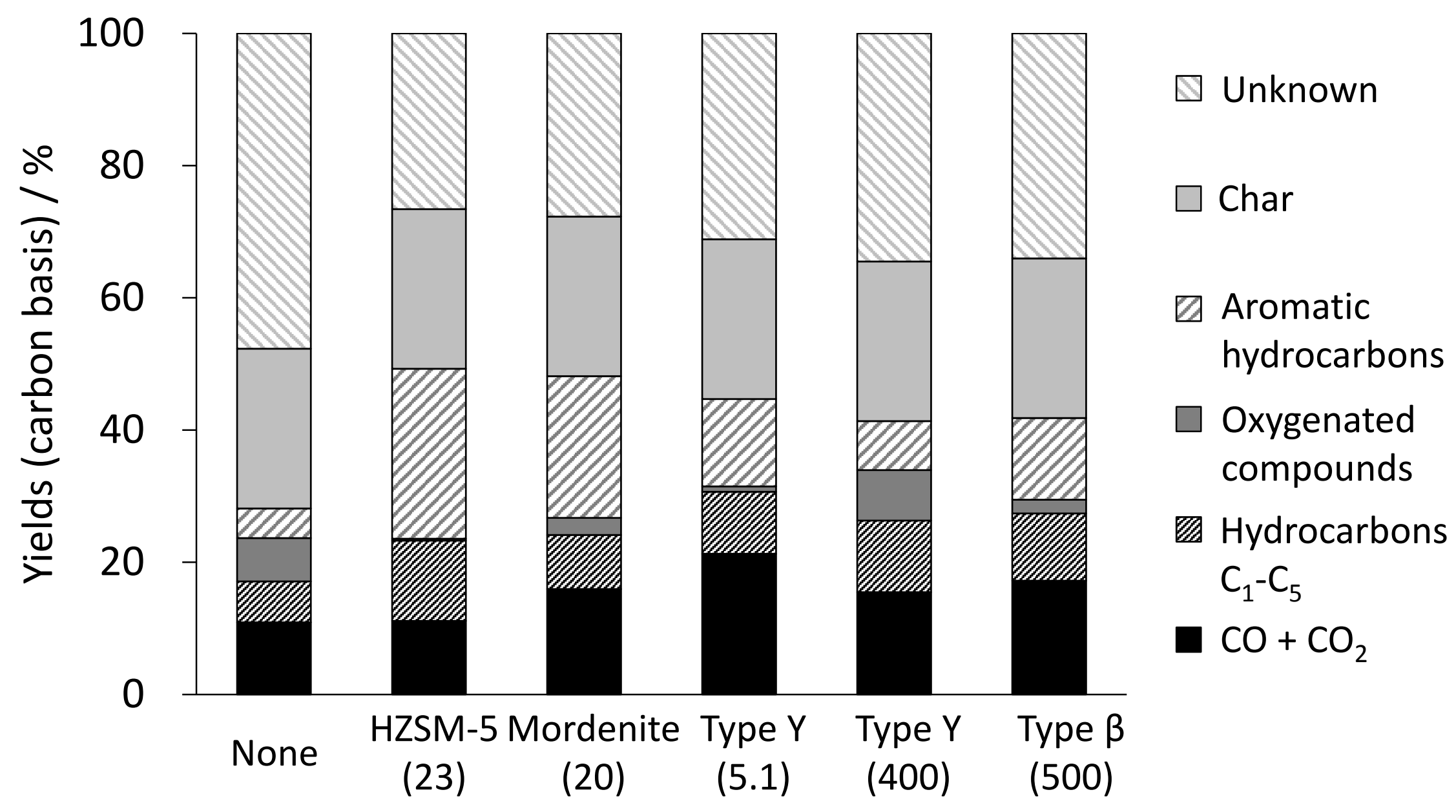

Fig.4. Uemura et al. 


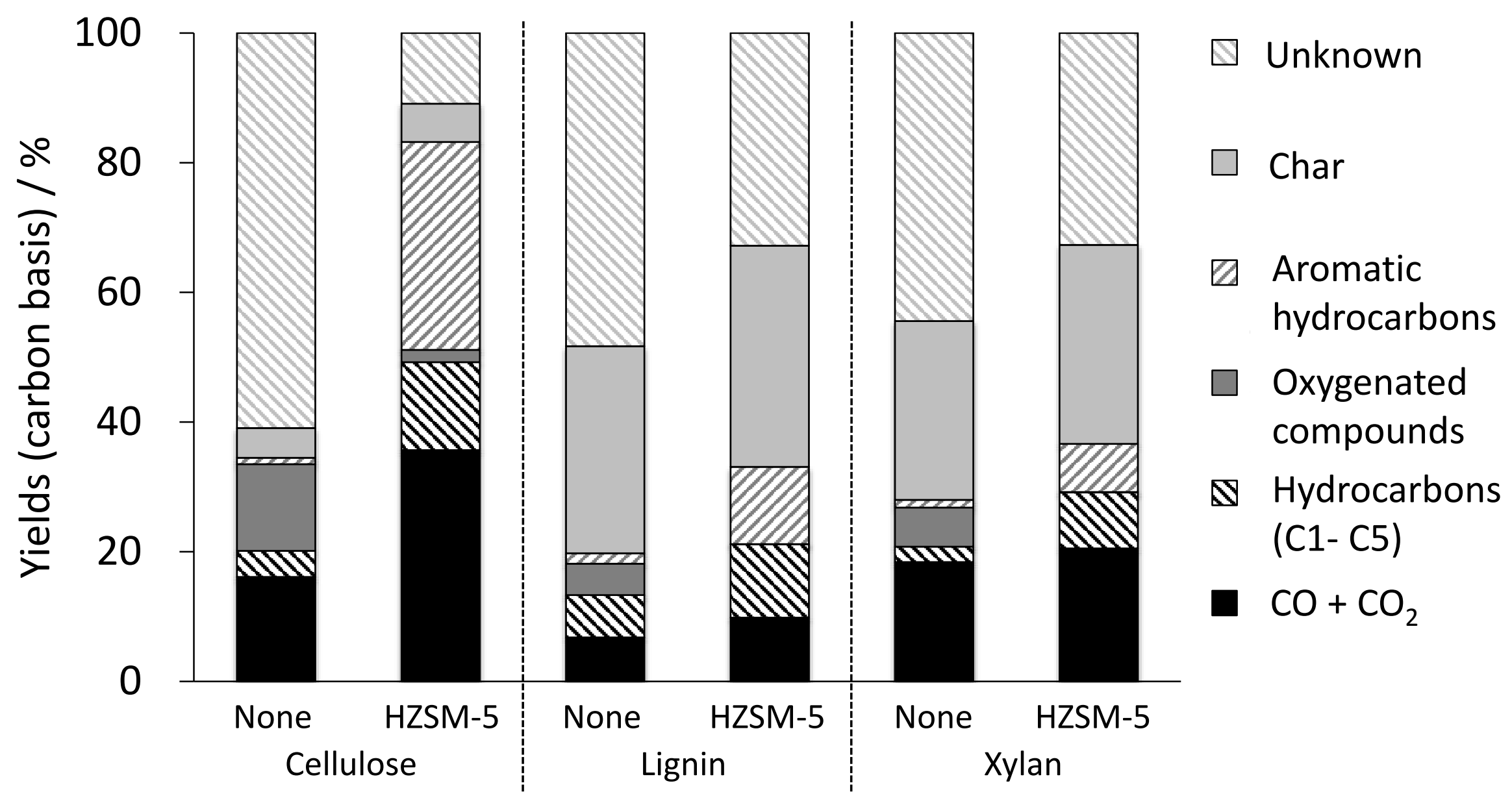

Fig.5. Uemura et al. 


\section{Primary compounds}

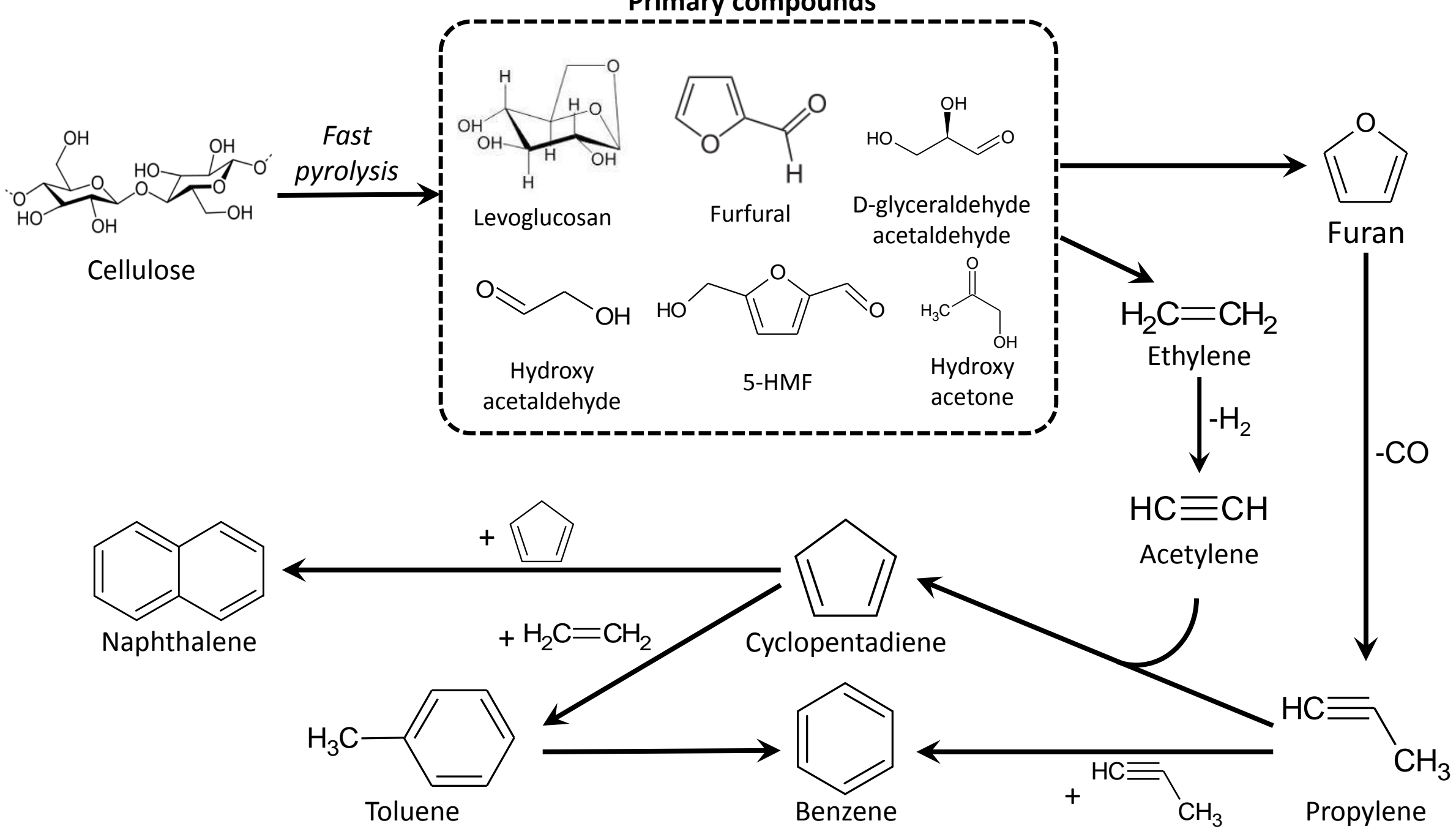

Fig.6. Uemura et al. 

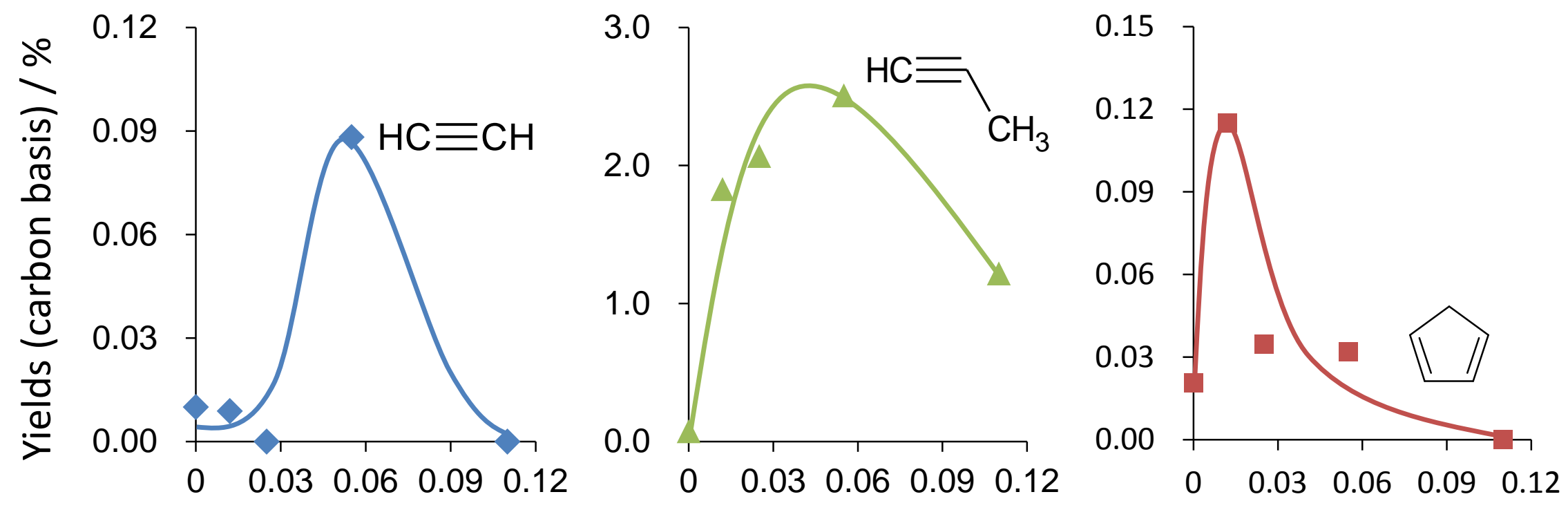

Amount of catalyst / $g$

Fig.7. Uemura et al. 